\title{
Association of geopotential height patterns with heavy rainfall events in Cyprus
}

\author{
F. Tymvios, K. Savvidou, and S. C. Michaelides \\ Meteorological Service, Nicosia, Cyprus \\ Received: 13 April 2009 - Revised: 14 April 2010 - Accepted: 11 June 2010 - Published: 23 June 2010
}

\begin{abstract}
Dynamically induced rainfall is strongly connected with synoptic atmospheric circulation patterns at the upper levels. This study investigates the relationship between days of high precipitation volume events in the eastern Mediterranean and the associated geopotential height patterns at $500 \mathrm{hPa}$. To reduce the number of different patterns and to simplify the statistical processing, the input days were classified into clusters of synoptic cases having similar characteristics, by utilizing Kohonen Self Organizing Maps (SOM) architecture. Using this architecture, synoptic patterns were grouped into 9, 18, 27 and 36 clusters which were subsequently used in the analysis. The classification performance was tested by applying the method to extreme rainfall events in the eastern Mediterranean. The relationship of the synoptic upper air patterns ( $500 \mathrm{hPa}$ height) and surface features (heavy rainfall events) was established, while the 36 member classification proved to be the most efficient.
\end{abstract}

\section{Introduction}

The island of Cyprus lies between latitude circles $34.6^{\circ}$ and $35.6^{\circ} \mathrm{N}$ and between meridians $32^{\circ}$ and $34.5^{\circ} \mathrm{E}$, surrounded by the eastern Mediterranean Sea. Its Mediterranean climate is characterized by the succession of a single rainy season (November to mid-March) and a single longer dry season (mid-March to October). This generalization is modified by

Correspondence to: F. Tymvios

(ftymvios@ms.moa.gov.cy) the influence of maritime factors, yielding cooler summers and warmer winters in most of the coastal and low-lying areas. Visibility is generally very good. However, during spring and early summer, the atmosphere is quite hazy, with dust transferred by the prevailing south-easterly to southwesterly winds from the Saharan and Arabian deserts, usually associated with the development of desert depressions (Michaelides et al., 1999).

There is a strong relationship between large scale circulation patterns and regional surface variables such as surface pressure, dynamical rainfall, wind and temperature. As a consequence, synoptic upper air charts at certain levels provide a valuable tool for the operational weather forecaster to predict qualitatively occurrences of heavy rainfall over particular areas. The height pattern at $500 \mathrm{hPa}$ (the so-called level of no divergence, according to Dine's simple two-level model of the atmosphere) is often used for this purpose. In order to take advantage of these semi-empirical methods and to simplify the statistical processing, stochastic downscaling methods are often applied to the actual weather patterns in order to generate clusters of synoptic cases with similar characteristics. Weather type classifications are simple, discrete characterizations of the current atmospheric conditions and they are commonly used in atmospheric sciences. For a review of various classifications, including their applications, refer to Key and Crane (1986), El-Kadi and Smithoson (1992), Hewitson and Crane (1996), Cannon and Whitfield (2002) and others.

There are several weather type classification techniques, developed for different regions and for different purposes. Many of them are based on automatic, objective and

Published by Copernicus Publications on behalf of the European Geosciences Union. 


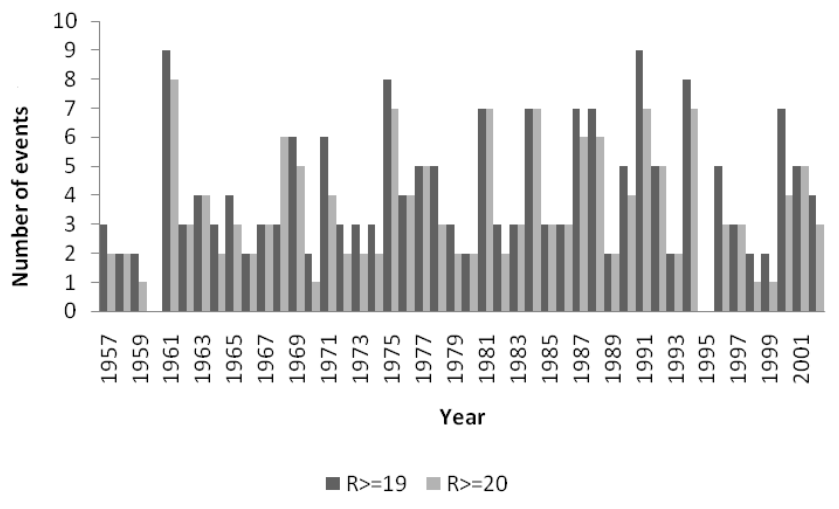

Fig. 1. The annual distribution of heavy rainfall events.

consistent methodologies. However, none of the proposed methods in the literature is accepted as universal and applicable for all problems. Each method has its strong and weak points. The method to be selected and its parameters are usually defined by the application itself. While Artificial Neural Networks (ANN) have proven to be valuable tools for forecasting purposes, Kohonen Self Organizing Maps (SOM) technique is a relatively new method for climate research (Main, 1997). Maheras et al. (2000) used a combination of an ANN classifier and semi-empirical methods for the classification of weather types in Greece, while Cavazos (1998) utilized a mixed architecture of a SOM network in line with a feed-forward ANN (FF-ANN) to study extreme precipitation events in Mexico and Texas. The same methodology was successfully applied for winter-time precipitation in the Balkans (Cavazos, 1999). In a research on dust events in the area of the eastern Mediterranean, a SOM neural network was utilized with an output of 36 clusters (Tymvios et al., 2007), while for forecasting the risk of extreme rainfall events, a 12 cluster classification was implemented (Tymvios et al., 2008). There is a wide ongoing European effort in evaluating different classification methods within the framework of COST Action 733, which is entitled "Harmonization of weather type classifications in Europe" (http://www.cost733.org/). The main objective of the Action is to achieve a general numerical method for assessing, comparing and classifying typical weather situations in European regions, scalable to any European sub-region with time scales between $12 \mathrm{~h}$ and 3 days and spatial scales of ca. 200 to $2000 \mathrm{~km}$.

The method exploited in the present work is the Kohonen Self Organizing Maps architecture which is a neural networks method with unsupervised learning (Kohonen, 1990). A detailed description of the method and procedures used is provided elsewhere (Michaelides et al., 2007).

The primary objective of this research is to present a nonlinear methodology for classifying synoptic patterns into distinct clusters and investigate possible relationships of such clusters with heavy rainfall events that were recorded in Cyprus.
Following this introduction, Sect. 2 describes the data and the methodology adopted and Sect. 3 gives a brief presentation of the ANN methodology adopted. The results are subsequently presented in Sect. 4. In this Section, a justification of the choice of the 36-cluster classification is provided, followed by a selection of important cases which can assist to evaluate the methodology proposed here. Conclusions are drawn in Sect. 5.

\section{Database and methodology}

The dataset used consists of mean daily rainfall values calculated from the daily rainfall values recorded at a network of 29 rain gauges of the Meteorological Service of Cyprus and for the period of 45 years from 1957 to 2002. At first, a quality control of the rain gauge data was carried out in order to remove stations with possible inconsistencies and inaccuracies. Such a homogenisation of the data is important for the extraction of sound results. In this investigation, a test of homogeneity based on the cumulative deviations from the mean is adopted (see Buishand, 1982). As a result of this analysis, five stations were removed from further study (from an examination of the history of some of these stations, it became evident that they have been subjected to relocations at one or more stages). The study was henceforth carried out with the remaining 23 stations (Michaelides et al., 2009). From the distribution of the frequency of the mean daily rainfall, the upper $5 \%$ of the distribution and the upper $10 \%$ of the distribution were calculated and are defined as the heavy rainfall thresholds for Cyprus; these thresholds are $20 \mathrm{~mm}$ (denoted as $R \geq 20$ ) and $19 \mathrm{~mm}$ (denoted as $R \geq 19$ ), respectively. The number of heavy rainfall days when the average rainfall over Cyprus exceeded the thresholds of $20 \mathrm{~mm}$ and $19 \mathrm{~mm}$ is 156 and 180 , respectively.

The annual distribution of the heavy rainfall events for $R \geq 19$ and $R \geq 20$ is presented in Fig. 1. On average, the annual occurrence of heavy rainfall events with $R \geq 20$ is 3.5 and for $R \geq 19$ is 4.1. In 1960 and 1995, no heavy rainfall events were recorded. The monthly occurrence of heavy rainfall events is shown in Fig. 2. Noticeably, the month with the most frequent heavy rainfall occurrences is December which is the month with the highest precipitation rates in Cyprus with $105.6 \mathrm{~mm}$ monthly average rainfall.

For the synoptic classification of weather patterns, data from the European Centre for Medium-range Forecasts (ECMWF) reanalysis project (ERA40) were used. More specifically, the dataset used consists of the 12:00 UTC $500 \mathrm{hPa}$ isobaric heights, in geopotential meters (gpm), at a resolution of $1^{\circ} \times 1^{\circ}$, over an area bounded by latitude circles $30^{\circ} \mathrm{N}$ and $76^{\circ} \mathrm{N}$ and meridians $37^{\circ} \mathrm{W}$ and $56^{\circ} \mathrm{E}$. The data refer to period from 1 October 1957 to 30 September 2002 and each day includes 48 rows $x 96$ columns which, for computational reasons, are reduced to $24 \times 32$ points, creating a two dimensional matrix with 768 elements. 


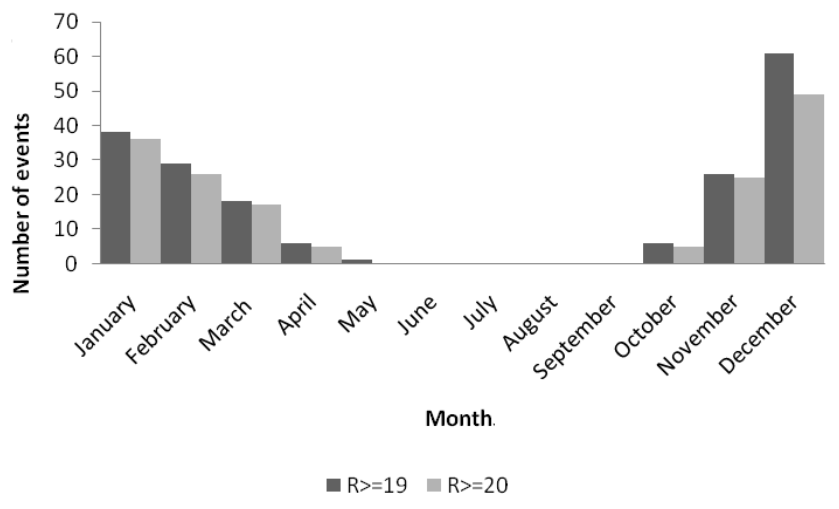

Fig. 2. Monthly occurrence of heavy rainfall events.

\section{Artificial Neural Networks}

Artificial Neural Networks (ANN) are constructions of artificial neurons (algorithms that mimic the properties of biological neurons). ANN are commonly used to solve artificial intelligence problems, to simulate and predict the evolution of complex physical systems, to discover hidden structures inside data groups and they are ideal for the classification of individuals into groups of similar properties. All of these are achieved according to the network's architecture and parameter tuning. The details of the classification method are discussed in Tymvios et al. (2010), hence, a short description is sufficient here.

The neural network architecture used in this work is the Kohonen Self Organizing Maps (Kohonen, 1990). Kohonen networks provide a way of representing multidimensional data in much lower dimensional spaces, usually one or two dimensions. An advantage of the SOM networks over other neural network classification techniques is that the Kohonen technique creates a network that stores information in such a way that any topological relationships within the training set are maintained, so even if the Kohonen network associates weather patterns with rainfall inaccurately, the error obtained will not be of great amplitude, since the result will be a class with similar characteristics. The process of reducing the dimensionality of height vectors is essential in order to investigate productively the relationship among weather patterns and heavy rainfall. The SOM architecture implemented is presented in Fig. 3, using Matlab's schematics (Demuth et al., 2008).

The number of outputs is not a priori determined, but an "optimum" can be adopted by experimentation, in relation to the specific application. In the present study, experimentation was carried out with various output values, arbitrarily considered as multiples of 9 . Hence, the output (i.e., the number of clusters as a result of the ANN classification) is set to $9,18,27$ or 36 .

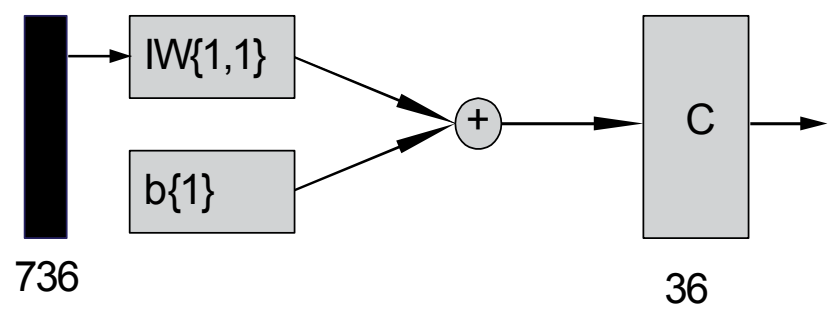

Fig. 3. A Kohonen Network built to classify a vector of 736 members into 36 clusters. The input vector is directed to the input weight matrix (IW $\{1,1\})$. The result is forwarded with the biases $(b\{1\})$ to the network which classifies the input vector accordingly.

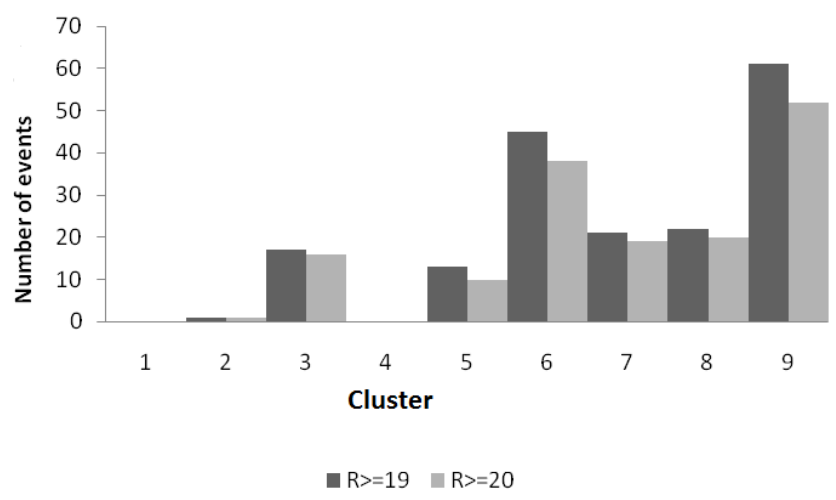

Fig. 4. Allocation of heavy rainfall events in the 9-cluster classification.

\section{Results}

\subsection{Choice of the 36-cluster classification}

The distribution of heavy rainfall events into clusters for the classification into 9, 18, 27 and 36 clusters is presented in Figs. 4-7, respectively. From Figs. 4-6, it is obvious that the classifications with 9,18 and 24 clusters are inadequate to account for the actual variability in the synoptic patterns for the European domain employed and their relation to heavy rainfall events in Cyprus. Simply, heavy rainfall events occur with almost all patterns, since events of heavy rainfall appear in almost all classes, in both the $R \geq 19$ and $R \geq 20$ distributions. Also, there is no clear distinction between winter and summer patterns, as one would expect from the dates that the actual synoptic conditions (not shown here).

In contrast to the above, the results for the 36-cluster classification (Fig. 7) exhibits the level of discretization required for the heavy rainfall events' association to specific synoptic patterns. Furthermore, in the 36-cluster classification, winter or transitional-season clusters are related to heavy rainfall, while summertime clusters (i.e., $6,11,12,17,18,23,24$, 30,35 and 36 ) have a zero probability of producing such an event (see also Tymvios et al., 2010). 


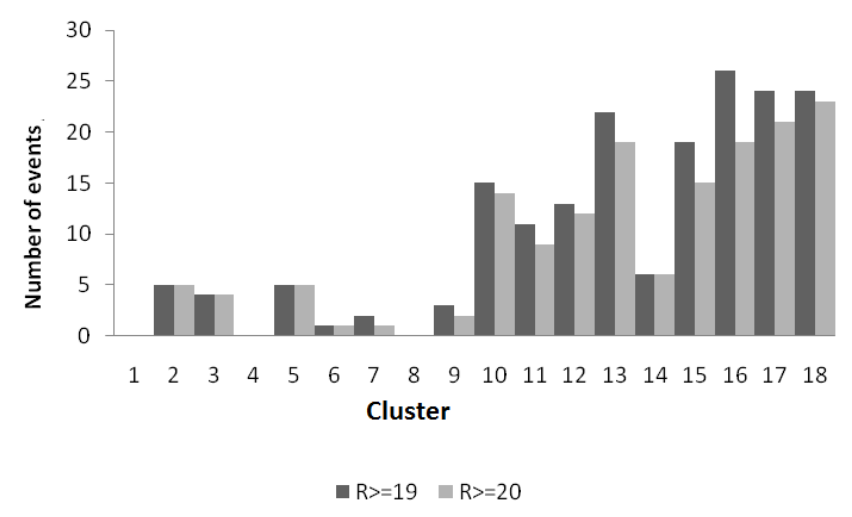

Fig. 5. Allocation of heavy rainfall events in the 18-cluster classification.

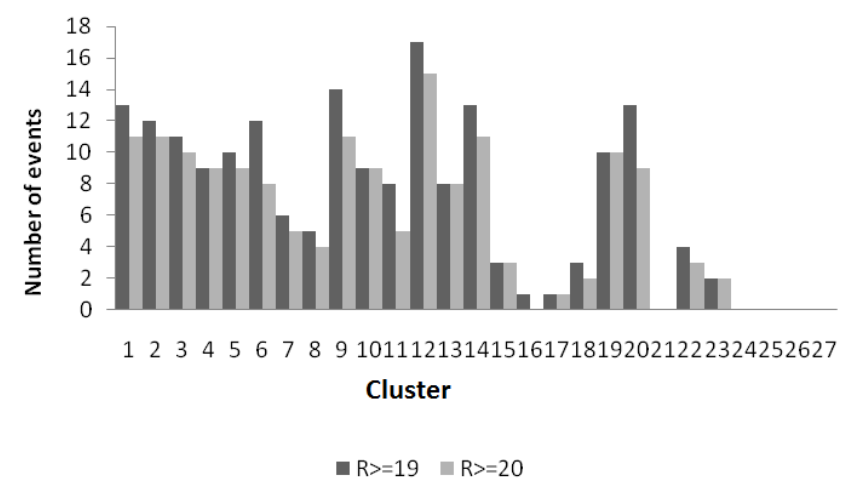

Fig. 6. Allocation of heavy rainfall events in the 27-cluster classification.

Eight clusters in the 36-cluster classification account for $65 \%$ of the heavy precipitation events for the $R \geq 20$ group; for the $R \geq 19$ group, the eight clusters account for $60 \%$ of the heavy precipitation events This implies that a comparatively small number of clusters characterizes most of the heavy rainfall events. Bearing in mind the above, it is intuitively inferred that the 36-cluster classification can form a basis for associating synoptic patterns and events of heavy rainfall. Thus, further investigation is focused on the 36cluster classification only.

In the following, some interesting cases are briefly presented, justifying the adopted classification. From an examination of these cases (and others not shown here) it became evident that the association of heavy rainfall events with the specific patterns is in line with the perception of an experienced weather forecaster.

\subsection{Cluster 1: highest frequency of events}

In the 36-cluster classification, Cluster 1 is the one that is most frequently associated with extreme rainfall events $(R \geq 20,13 \% ; R \geq 19,14 \%)$, followed by Cluster $9(R \geq 20$, $10 \% ; R \geq 19,8 \%)$.

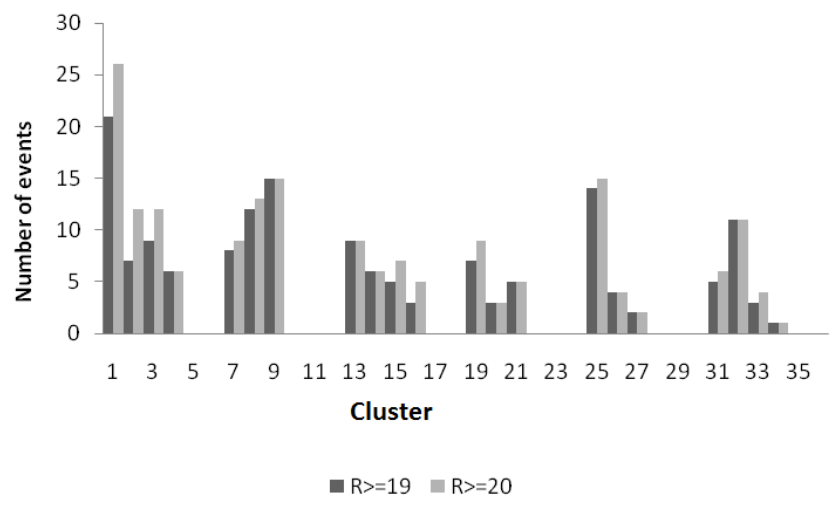

Fig. 7. Allocation of heavy rainfall events in the 36-cluster classification.

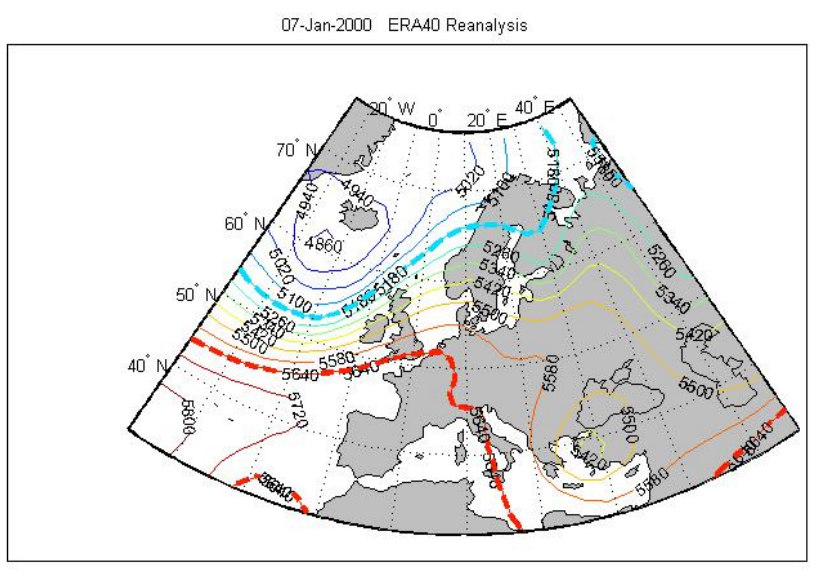

Fig. 8. Typical geopotential height distribution pattern for Cluster 1, on 7 January 2000 (unit: gpm).

For brevity, a typical case of a synoptic situation falling under Cluster 1 is outlined. Figure 8 depicts the synoptic situation that affected the study area on 7 January 2000, when a deep cut-off low centred over western Turkey maintained a west to southwest flow over Cyprus area while an upper ridge affected West and Central Europe. The geopotential height over Cyprus was around 5530 gpm.

\subsection{Extreme heavy rainfall events}

Table 1 shows the three most rainy days in the 45 year period studied and the corresponding clusters they belong to. On these days, the average rainfall recorded was over $60 \mathrm{~mm}$. Thus, significant average rainfall amount over $60 \mathrm{~mm}$ was recorded on 1 December 1957, 2 December 2001 and 1 December 1992; their corresponding synoptic patterns are represented by Cluster $32(66.2 \mathrm{~mm})$, Cluster $9(62.3 \mathrm{~mm})$ and Cluster $7(61.0 \mathrm{~mm})$, respectively. For each of these three days, the geopotential height pattern is displayed in Figs. 911. It is worth noting that all of the three events occurred in 
01-Dec-1957 ERA40 Reanalysis

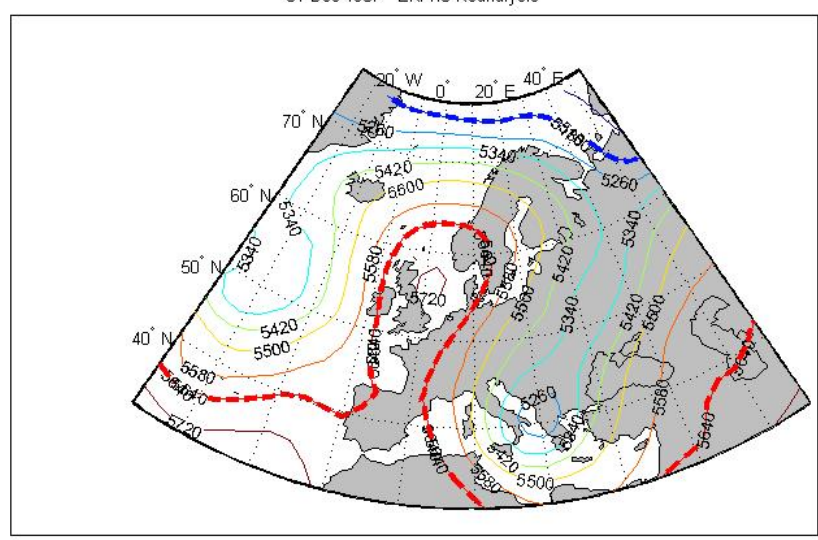

Fig. 9. Geopotential height pattern on 1 December 1957 (Cluster 32) with an average rainfall of $66.2 \mathrm{~mm}$ (unit: gpm).

02-Dec-2001 ERA40 Reanalysis

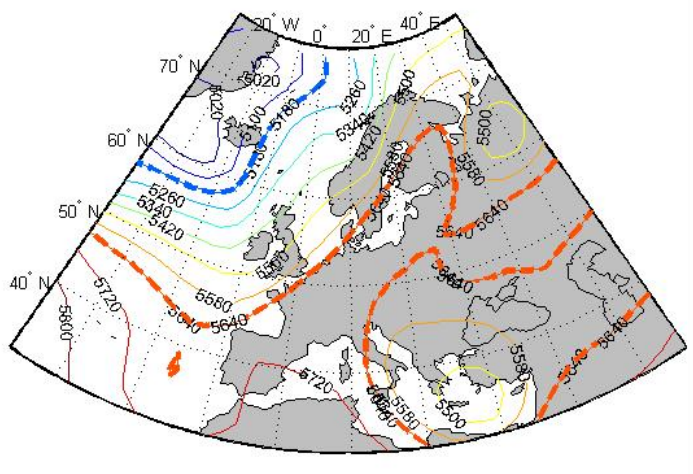

Fig. 10. Geopotential height pattern on 2 December 2001 (Cluster 9) with an average rainfall of $62.3 \mathrm{~mm}$ (unit: gpm).

December. An outline of the main upper air features for each of these three cases is given below.

On 1 December 1957 (Fig. 9), an omega-blocking pattern dominates the general circulation of the Northern Hemisphere covering the Atlantic Ocean and Europe. At the east side of the omega-blocking, there is a deep cut-off low with its centre located over south Albania affecting the weather of Central and East Europe and the countries of Central and East Mediterranean. The upper trough remained stationary for 4 days and produced record-high volumes of rainfall over the island of Cyprus.

On 2 December 2001 (Fig. 10), an upper ridge affected the west and central Europe while warm humid air from the Mediterranean Sea remained essentially stagnant over the eastern Mediterranean. The upper low was centred between Crete and Cyprus with a height around $5500 \mathrm{gpm}$ and with an associated with a surface low. The upper low had been cut off from the general circulation over central Europe and was
01-Dec-1992 ERA4D Reanalysis

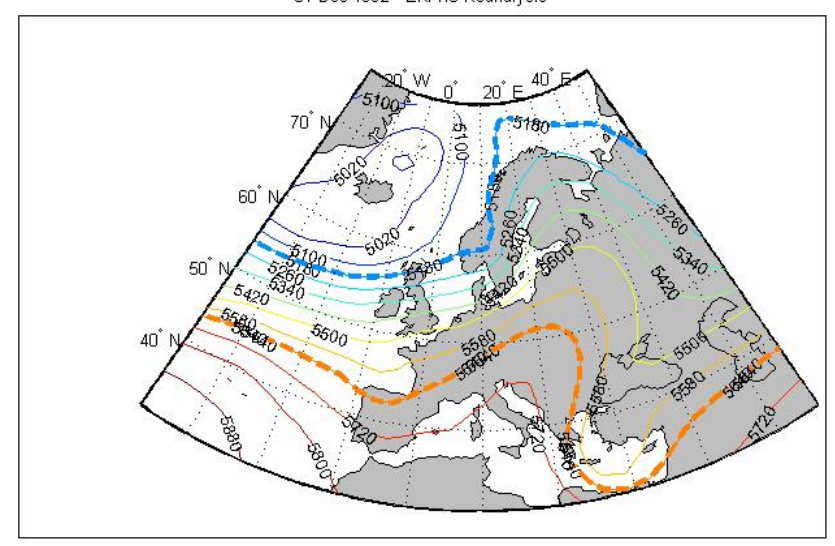

Fig. 11. Geopotential height pattern on 1 December 1992 (Cluster 7) with an average rainfall of $61.0 \mathrm{~mm}$ (unit: gpm).

Table 1. Events with the most extreme values of rainfall (exceeding $60 \mathrm{~mm}$ ); the corresponding Cluster numbers refer to the 36-cluster classification.

\begin{tabular}{ccc}
\hline Date & $\begin{array}{c}\text { Average } \\
\text { rainfall } \\
(\mathrm{mm})\end{array}$ & Cluster \\
\hline 1 Dec 1957 & 66.2 & 32 \\
2 Dec 2001 & 62.3 & 9 \\
1 Dec 1992 & 61.0 & 7 \\
\hline
\end{tabular}

subsequently progressing eastwards and filling. This system produced an average rainfall amount of $62.3 \mathrm{~mm}$.

On 1 December 1992 (Fig. 11), a diffluent trough over the eastern Mediterranean, with its axis orientation from Northeast to Southwest, affected the area of Cyprus. An upper ridge extended from the central Mediterranean all the way into Russia, providing the area of east Mediterranean with cold air aloft, creating extremely unstable conditions and resulting in $61 \mathrm{~mm}$ of average rainfall.

\section{Concluding remarks}

The objective of this work was to associate synoptic weather features with heavy rainfall events in the area of the Eastern Mediterranean. This was achieved with the classification of geopotential height patterns at $500 \mathrm{hPa}$ in 9,18 , 27 and 36 clusters, by using Artificial Neural Networks. The Kohonen Self Organizing architecture (SOM) was adopted, over a wider European domain, adequately encompassing all synoptic features that could potentially affect the eastern Mediterranean. The most appropriate classification proved to be the pattern classification with 36 clusters. 
From the selected cases presented above but also from a wider examination of many other individual cases, the association of heavy rainfall events with the specific patterns is in good agreement with the weather forecaster's perception of which synoptic situations can lead to excessive precipitation events (which, however, is not confined to a single upper-air chart).

A similar evaluation approach was conducted for the classification of the mean sea level pressure patterns with 9,18 , 27 and 36 clusters but the results were ambiguous, with no particular cluster emerging as likely to be associated with heavy rainfall events.

Acknowledgements. This study was supported by the Project FLASH, which is funded by the European Union (Sixth Framework Programme, Contract No. 036852).

Edited by: K. Nicolaides and A. Orphanou

Reviewed by: two anonymous referees

\section{References}

Buishand, T. A.: Some methods for testing the homogeneity of rainfall records, J. Hydrol., 58, 11-27, 1982.

Cannon, J. A. and Whitfield, P. H.: Synoptic map-pattern classification using recursive partitioning and principal component analysis, Mon. Weather Rev., 130, 1187-1206, 2002.

Cavazos, T.: Large-scale circulation anomalies conducive to extreme precipitation events and derivation of daily rainfall in Northeastern Mexico and Southeastern Texas, J. Climate, 12, 1506-1523, 1999.

Cavazos, T.: Using self-organizing maps to investigate extreme climate events: An application to wintertime precipitation in the Balkans, J. Climate, 13, 1718-1732, 2000.

Demuth, H., Beale, M., and Hagan, M.: Neural Network Toolbox 6 User's Guide, The Mathworks Inc., 2008.
El-Kadi, A. K. A. and Smithoson, P. A.: Atmospheric classifications and synoptic climatology, Prog. Phys. Geog., 16, 432-455, 1992.

Hewitson, B. C. and Crane, R. G.: Climate downscaling: Techniques and application, Clim. Res., 7, 85-95, 1996.

Kohonen, T.: The Self-Organizing Map, P. IEEE, 78(9), 14641480, 1990.

Key, J. and Crane, R. J.: A Comparison of Synoptic classification schemes based on "objective" procedures, J. Climatol., 6, 375388, 1986.

Maheras, P., Patrikas, I., Karakostas, T., and Anagnostopoulou, C.: Automatic classification of circulation types in Greece: methodology, description, frequency, variability and trend analysis, Theor. Appl. Climatol., 67, 205-223, 2000.

Main, J. P. L.: Seasonality of circulation in Southern Africa using the Kohonen self organizing map, M. S. thesis, Department of Environmental and Geographical Sciences, University of Cape Town, South Africa, 84 pp., 1997.

Michaelides, S. C., Evripidou, P., and Kallos, G.: Monitoring and predicting Saharan desert dust transport in the eastern Mediterranean, Weather, 54, 359-365, 1999.

Michaelides, S. C., Pattichis, C. S., and Kleovoulou, G.: Classification of rainfall variability by using artificial neural networks, Int. J. Climatol., 21, 1401-1414, 2001.

Michaelides, S. C., Liassidou, F., and Schizas, C. N.: Synoptic classification and establishment of analogues with artificial neural networks, Pure Appl. Geophys., 164, 1347-1364, 2007.

Michaelides, S. C., Tymvios, F. S., and Michaelidou, T.: Spatial and temporal characteristics of the yearly rainfall frequency distribution in Cyprus, Atmos. Res., 94, 606-615, 2009.

Tymvios, F. S., Constantinides, P., Retalis, A., Michaelides, S., Paronis, D., Evripidou, P., and Kleanthous, S.: The AERAS project - database implementation and Neural Network classification tests, Proceedings of the 6th International Conference on Urban Air Quality Limassol, Cyprus, 27-29 March 2007, 2007.

Tymvios, F., Michaelides, S., and Charalambous, D.: Investigation of trends in synoptic patterns over Europe with artificial neural networks, Adv. Geosci., submitted, 2010. 